\title{
Pharmacognostic Studies and Nephroprotective Potential of Hy- droalcoholic Extract of Trichosanthes cucumerina in Acute Renal Failure
}

\author{
Doppalapudi Prasanthi, Sreedevi Adikay
}

Doppalapudi Prasanthi*,

Sreedevi Adikay,

Sri Padmavathi Mahila Visvavidyalayam

Research Scholar

Institute of Pharmaceutical Technology Tirupati-517502 Andhra Pradesh, INDIA.

Professor, Institute of Pharmaceutical

Technology, Tirupati-517502 Andhra

Pradesh, INDIA.

Correspondence

\section{Doppalapudi Prasanthi}

Institute of Pharmaceutical Technology Tirupati-517502 Andhra Pradesh, INDIA.

Phone: 09492077949

E-mail: prasanthi.doppalapudi@gmail. com

\section{History}

- Submission Date: 27-9-2016;

- Review completed: 12-12-2016;

- Accepted Date: 20-12-2016.

DOI : 10.5530/pj.2017.2.29

Article Available online

http://www.phcogj.com/v9/i2

\section{Copyright}

(C) 2017 Phcog.Net. This is an openaccess article distributed under the terms of the Creative Commons Attribution 4.0 International license.

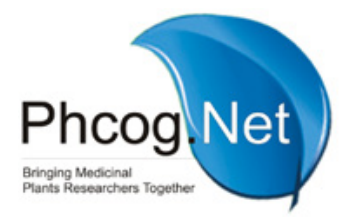

\begin{abstract}
Objective: The present research work unearthed not only pharmacognostic features of the seeds of Trichosanthes cucumerina but also the nephroprotective activity of $60 \%$ hydro alcoholic extract against Cisplatin-induced Wistar rat model. Materials and methods: Present study dealt with the detailed pharmacognostic study of the seeds of Trichosanthes cucumerina. $60 \%$ hydro alcoholic extract was prepared by hot extraction method. Preliminary phytochemical screening was carried out. Based on acute toxicity studies nephroprotective effect of the extract was screened at 200 and $400 \mathrm{mg} / \mathrm{kg}$, b. w. in curative and prophylactic regimen. Nephrotoxicity was induced in male Wistar rats by administration of Cisplatin $(5 \mathrm{mg} / \mathrm{kg}$, b.w. i.p. as a single dose). Nephroprotective activity was assessed by estimating serum markers and urinary functional parameters supported by anti-oxidant studies and histopathological aspects. Results: Microscopic studies showed that the seed coat had outer aerenchymatous tissue, inner parenchymatous tissue and innermost compact lines of sclereids. Physicochemical evaluation yielded alcohol and water soluble extractive values of 20.8 and $8.05 \% \mathrm{w} / \mathrm{w}$. Total ash, acid insoluble and water soluble ash values were $7.15,6.45$ and 0.5 respectively. Fluorescence analysis imparted characteristic colours to the seed powder when observed under visible and UV light. Cisplatin-induced nephrotoxicity was indicated by increased levels of serum markers and urinary functional parameters which were reversed by the extract in dose dependent manner. The results were substantiated by anti-oxidant studies and histopathological studies. Conclusion: Various pharmacognostic parameters evaluated assisted in identification and standardization of seeds of Trichosanthes cucumerina in crude form. Present study revealed that hydroalcoholic extract attenuated the nephrotoxicity and provided the strengthened scientific evidence for the use of seeds of Trichosanthes cucumerina in nephrotoxicity.
\end{abstract}

Key words: Anti-oxidants, Cisplatin, Histopathological studies, Pharmacognostic studies, Trichosanthes cucumerina.

\section{INTRODUCTION}

Plants play an eminent role in maintaining human health and contribute towards progress of human life. They are important components of medicines, cosmetics, dyes, beverages, etc. In the present scenario, focus on plant search has increased all over the globe enormously. Many a plant species are obtainable with food potential of offering direct therapeutic effect individually or in combinations. Ethnobotanical and ethnopharmacological studies on such plants contribute to attract researchers all over the world.

Day by day the number of people suffering from kidney disorders is increasing at an alarming rate especially nephrotoxicity caused by drugs has now become a common factor. Nephrotoxicity of the drugs is frequently associated with their accumulation in renal cortex, dependent upon their affinity to kidneys and on kinetics of drug trapping process. ${ }^{1}$ In addition to drugs age, diabetes, hypertension, liver disease, oliguria, etc., also stand as the major risk factors of acute renal failure. These toxic agents include antibiotics like Gentamicin, anti-cancer agents like Cisplatin, doxorubicin, radio contrast agents, etc. In case of these drugs, nephrotoxicity remains as a major clinical limitation. Cisplatin is one of the most extensively used anti-cancer drugs which induce free radical production causing oxidative renal injury in proximal uriniferous tubules, possibly due to depletion of anti-oxidant systems and lack of tumour tissue selectivity. Greater degree of accumulation of Cisplatin occurs in the organ kidney especially in the proximal tubular epithelial cells and results in nephrotoxicity. Highest concentration of cisplatin is noticed in the S3 segment of the proximal tubule followed by the distal collecting tubule and the $\mathrm{S} 1$ segment in the proximal tubule. ${ }^{2}$ A minimum dose of Cisplatin ( $5 \mathrm{mg} / \mathrm{kg}$ b.w.) was sufficient to induce nephrotoxicity in rats. ${ }^{3}$ So it is very crucial to prevent the AKI and help in the improvement of kidney functioning by use of alternatives. But no drug in allopathy is able to combat this renal toxicity efficiently. This dire need for nephroprotective agents results in exploitation of medicinal plants. Co-administration of medicinal plants along with cisplatin may reverse its nephrotoxicity. Previously it was reported that plants like Bauhinia variegata, Cassia auriculata, Pongamia pinnata, Cucurbita 
pepo, etc. possess significant nephroprotective activity against cisplatininduced nephrotoxicity. ${ }^{4}$

\section{Trichosanthes cucumerina}

Belonging to the family Cucurbitaceae is one such well-known Ayurvedic herb used as a vegetable and also has medicinal properties. Trichosanthes cucumerina is a climbing herbaceous vine with $40-120 \mathrm{~cm}$ long fruits. The fruits are pale-green and orange when ripe. Single fruits weigh about $0.5-1 \mathrm{~kg}$, and contain 40-70 seeds.

\section{Taxonomy}

Kingdom- Plantae

Phylum- Embryophyta

Class- Dicotyledoneae

Order: Cucurbitales

Family: Cucurbitaceae

Genus: Trichosanthes

\section{Species: cucumerina}

Commonly it is known as Snake gourd, Serpent gourd, potlakaya, aduvalakaayi, pudalankaai, chichinga and padwal. ${ }^{5,6}$ Fruit is considered to be cooling, anthelmintic and used as purgative and emetic. Leaf is astringent, emetic and diuretic. The leaves and stems are used for bilious disorders and skin diseases. Root is abortifacient, anthelmintic, astringent, anti-septic, diuretic and emetic. Its seeds were used by folklore of Rayalaseema for their cooling property and diuretic effect.7,8

To date no systematic study has been carried out on the detailed pharmacognostic studies and nephroprotective effect of seeds of Trichosanthes cucumerina. Therefore present work was planned to carry out pharmacognostic studies and evaluate nephroprotective efficacy of seeds of Trichosanthes cucumerina against cisplatin-induced model.

\section{MATERIALS AND METHODS}

\section{Collection and authentication of plant material}

Seeds of Trichosanthes cucumerina were purchased from Narayana \& Co., Madanapalle, A. P. Their authentication was confirmed by Botanist, Dr. Madhavachetty, Department of Botany, Sri Venkateswara University, Tirupati. A voucher specimen (No: 1520) of the plant was deposited in herbarium of Department of Botany, Sri Venkateswara University, Tirupati.

\section{Macromorphological Description}

The seeds of Trichosanthes cucumerina were subjected to macroscopic studies which comprised of organoleptic characteristics viz. color, appearance, shape, texture, etc. of the drug. These parameters are considered as quite useful in quality control of the crude drug and were evaluated according to standard procedures. ${ }^{9-11}$

\section{Microscopic studies}

\section{Sectioning}

The paraffin embedded seeds were sectioned with the help of Rotary Microtome. The thickness of the section was 10 to $12 \mu \mathrm{m}$. Dewaxing of the section was done by customary procedure. ${ }^{12}$ The sections were stained with toluidine blue. ${ }^{13}$ The dye rendered pink colour to the cellulose walls, violet to the mucilage, blue to the lignified cells, dark green to suberin, blue to the protein bodies, etc.

\section{Photomicrographs}

Photographs of different magnifications were taken with Nikon Labphoto 2 microscopic unit. Bright field was used for normal observations. Polarized light was employed for the study of crystals, starch grains and lignified cells. Since these structures have birefringent property, under polarized light they appear bright against dark background. Magnifications of the figures are indicated by the scale bars. Descriptive terms of the anatomical features are as mentioned in the standard anatomy books. ${ }^{14}$

\section{Powder Microscopy}

Powder microscopy was carried out for the seed powder and specific diagnostic characters were recorded.

\section{Physicochemical analysis}

Crude powdered drug of seeds of Trichosanthes cucumerina was used for the determination of various physicochemical parameters such as total ash value, acid insoluble ash value, water soluble ash value, foreign matter, $\mathrm{pH}$, moisture content and extractive values.

\section{Fluorescence analysis}

The fluorescence characters of the powdered seeds of Trichosanthes cucumerina with different chemical reagents were studied by observing under day light and UV light. ${ }^{15}$

\section{Preparation of plant extract}

Seeds were shade dried and powdered in Wiley mill. Seed powder was macerated with ethanol and water in the ratio of 60:40 for $24 \mathrm{~h}$ and refluxed for $3 \mathrm{~h}$, then filtered and subjected to distillation under reduced pressure. This procedure was repeated for three times. Then the extracts were combined, air dried and allowed to concentrate under reduced pressure to get the semi-solid residue. It was stored in desiccator and used for preliminary phyto-chemical screening and pharmacological studies.

\section{Preliminary phytochemical screening}

Preliminary phytochemical studies were carried out for the hydroalcoholic extract as per standard procedures for the presence of various phyto constituents like alkaloids, flavonoids, saponins, glycosides, proteins, tannins, terpenoids, steroids, carbohydrates, fats and oils, etc. ${ }^{16}$

\section{Chemicals}

Cisplatin (Celplat) was purchased from local dealers. All other chemicals used in the present study were of analytical grade.

\section{Animals}

Eight week old adult male albino rats (150-200gm) of Wistar strain were obtained from Sri Venkateswara Enterprises, Bangalore and housed in polypropylene cages in a ventilated room at $25 \pm 2^{\circ} \mathrm{C}$ under a $12 \mathrm{~h}$ light/dark cycle. The animals were acclimatized for one week before the start of study and maintained with standard rat pellet food and water ad libitum. The experimental protocol was approved by the Institutional animal ethical committee (IAEC). Registration number and date of registration was 1677/PO/a/12/CPCSEA/Dec-14/11. CPCSEA (Committee for the purpose of Control and Supervision of Experiments on animals) guidelines were followed for animal handling and treatment.

\section{Acute toxicity studies}

OECD 423 guidelines were followed to carry out acute toxicity studies. ${ }^{17}$ All the animals of the group received single dose of hydroalcoholic extract $(2000 \mathrm{mg} / \mathrm{kg} \mathrm{p.} \mathrm{o.)} \mathrm{After} \mathrm{administration} \mathrm{of} \mathrm{extract} \mathrm{animals} \mathrm{were}$ observed continuously and individually for 30 minutes, 2 hours and 24 
hours to detect changes in the autonomic or behavioural responses and also for tremors, convulsions, salivation.

\section{Experimental Design}

To study the protective effect of hydroalcoholic extract of seeds of Trichosanthes cucumerina against Cisplatin-induced nephrotoxicity, 48 male Wistar rats were randomly enrolled into 8 equal groups and treated as following: Group-I was kept normal by administering only vehicle. Group-II was kept as curative control and subjected to cisplatin administration at a dose of $5 \mathrm{mg} / \mathrm{kg}$, b.w. intra-peritoneally (single dose). Group-III and Group-IV were administered orally via gavage with lower and higher doses of the hydroalcoholic extract i.e., 200 and $400 \mathrm{mg} / \mathrm{kg}$, b.w. from day 5 to day 9. Group-V is the prophylactic control which is administered with Cisplatin on day 5. Group-VI and Group-VII were administered with lower and higher doses of the hydroalcoholic extract i.e., 200 and $400 \mathrm{mg} / \mathrm{kg}$, b.w. from day 1 to day 5 . In the curative regimen rats were initiated with intra-peritoneal injection of Cisplatin at a dose of $5 \mathrm{mg} / \mathrm{kg}$,b.w. (single dose) on day 1 and in the prophylactic regimen Cisplatin was administered on day 5 with one hour gap of oral administration of hydroalcoholic extract. Group-VIII served as standard which was administered with Cisplatin on day 1 and Cystone $(5 \mathrm{ml} / \mathrm{kg}$, b.w.) from day 5 to day 9 .

\section{Biochemical Studies}

On day 5 and day 9, urine was collected by keeping rats individually in metabolic cages; on following day animals were sacrificed by cervical decapitation. Blood samples were collected by cardiac puncture and used for estimation of serum markers. Kidneys were isolated and left kidney was used for assessing antioxidant parameters and right kidney for histopathological studies.

Biochemical parameters such as Blood Urea Nitrogen (BUN) was estimated by Diacetyl mono-oxime method, Serum Creatinine (SC) by Jaffe's Alkaline picrate method, Serum total proteins $\left(\mathrm{S}_{\mathrm{TP}}\right)$ and Urinary total proteins $\left(\mathrm{U}_{\mathrm{TP}}\right)$ by Turbidity method and Creatinine clearance $\left(\mathrm{Cl}_{\mathrm{Cr}}\right)$ by Alkaline picrate method. These estimations were done using commercial kits. ${ }^{18}$

\section{Anti-oxidant studies}

To the weighed portions of the kidneys, ice cold $0.05 \mathrm{M}$ phosphate buffer of $\mathrm{pH} 7.8$ was added and homogenized to obtain a $20 \%(\mathrm{w} / \mathrm{v})$ homogenate. The obtained homogenates were centrifuged at $10,000 \mathrm{rpm}$ for $15 \mathrm{~min}$ and the clear supernatant attained was used for the analysis of antioxidant enzymes. Anti-oxidant studies were carried out by the estimation of levels of catalase (Cohen et al., 1970), superoxide dismutase (Saggu et al., 1989), reduced glutathione, (Ellman et al.,1959), and lipid peroxidation (Ohkawa et al., 1979). ${ }^{19-22}$

\section{Histopathological studies}

Kidneys of two animals from each group were used for histological studies. The isolated kidneys were fixed in $10 \%$ buffered formalin and processed to paraffin wax. Sections were stained with haematoxylin and eosin and were examined under light microscope.

\section{Statistical analysis}

The statistical data was expressed as mean \pm SEM. Parametric data which include all the biochemical parameters were analyzed using one way Analysis of variance (ANOVA) and compared using Tukey-Kramer multiple comparison tests. A probability value of $\mathrm{p}<0.05$ was considered as significant.

\section{RESULTS}

\section{Macroscopy}

Seeds are about $1.5 \mathrm{~cm}$ long and $0.9 \mathrm{~cm}$ wide. They are greyish brown in colour with half-ellipsoidal shape and compressed, flat. Their seed coat is hard and rugulose.

\section{Microscopy}

The seeds were compressed and flat, ellipsoidal in shape. The seed coat was woody and rugulose. There was a central median, pale vertical region. On either side of the central part were irregular highly depressed zones. The marginal part of the seed was forming prominent ridges and furrows. (Figure 1.1)

\section{Longitudinal section of the seed}

In a paracotyledonary section, the cotyledon appeared flat and wide with the margins of the seed coat being ridged and furrowed. (Figure 1.2)

When the seed was cut vertically, at right angles to the flat surface of the seed, the seed had straight, smooth, parallel opposite side with exostoma and endostoma (outer and inner micropylar openings) (Figure 1.3). The seeds were $30 \mu \mathrm{m}$ thick.

\section{Transverse section of the seed}

The outer seed coat had compact, angular thin walled parenchyma zone along the lateral part and covered by inner seed coat which was differentiated into outer wavy surface and innermost layer of sclerenchyma cells. At the end portions of the seed, the seed coat consisted of aerenchymatous tissue with wide air chambers and thin partition filaments. Within the seed were seen thin endosperm and cotyledons of the embryo. (Figure 2.1)

In paracotyledonary section of the seed, one end of the seed was wider than the opposite end. (Figure 2.2).

The embryo was in the form of thick segment located in the chamber of seed coats.

The seed coat consisted of outer epidermis, next layer of thin walled palisade cells followed by thick layer of parenchyma cells. The sclerenchyma layers continued as in the upper part of the seed. Endosperm was in thin layer attached with the inner surface of the embryonal chamber. (Figure 2.3)

Figures 2.4 - 2.9 had shown detailed structure of the seed coat in enlarged view. The micropylar passage was surrounded by a thick sclerenchymatous sheath (Figure 2.4) and the sclerenchyma layer extended below the seed and was reduced to layers (Figure 2.5, 2.6)

Figure 2.7-2.9 showed well preserved more details of the seed. The seed consisted of two flat, parallel cotyledons which had thin walled parenchyma cells. (Figure 2.7), innermost parenchymatous sarcotesta or inner seed coat where there were small vascular strands composed of xylem and phloem elements.

The outer seed coat comprised of multiple layer of epidermis, single wide layer of palisade cells and wide squarish zone of inner seed coat which had smaller, angular, slightly thick walled parenchyma cells. (Figure 2.8, 2.9)

\section{Powder Microscopy}

Powder preparation of the seed exhibited the following elements:

Parenchymatous tissue of the seed coat: Small fragments of parenchyma cells of the seed coat were seen in surface view. (Figure 3.1, 3.2) The cells were polyhedral and thin walled. The cells included many storage products: oil bodies of various sizes were abundant in the powder. (Figure 3.2) 

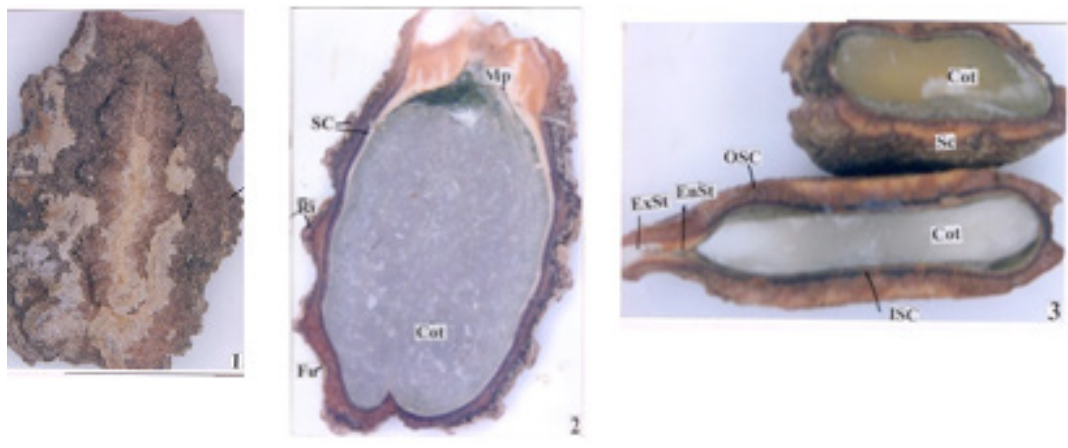

Figure 1: 1.1: Seed: surface view of the seed $; 1.2$ : Longitudinal section of the seed parallel to the cotyledon 1.3 A:T.S. of the seed -at right angles to the vertical axis of the seed; $1.3 \mathrm{~B}$ : Vertical section-at right angles to the cotyledons
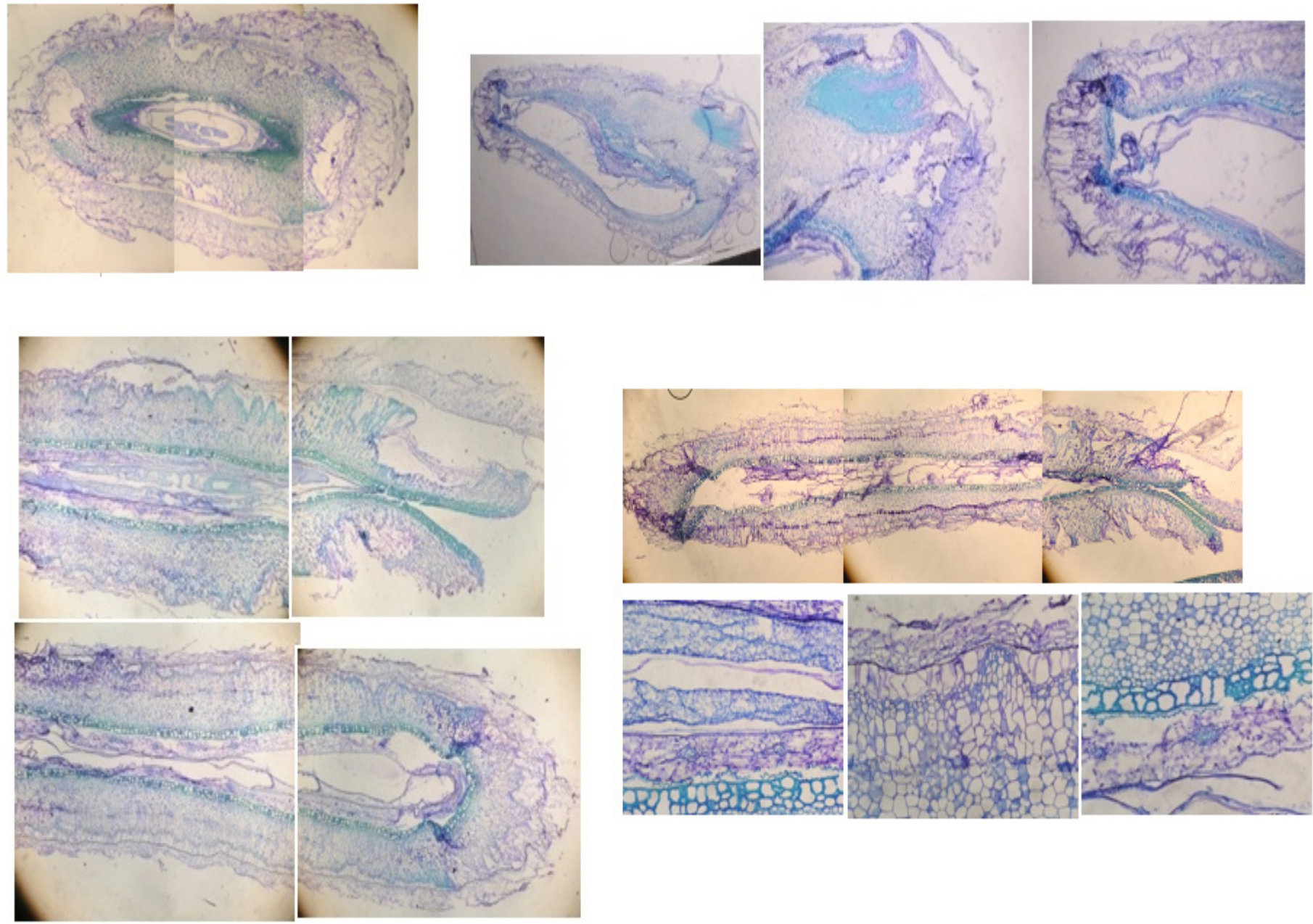

Figure 21.-2.10: 2.1:Transverse section of the seed ; 2.2: Paracotyledonary section of the seed ; 2.3: L.S. of the seed-Upper lateral part enlarged; 2.4 : Narrow end of the seed-enlarged; 2.5 : Vertical section of the seed-at right angles to the flat surface of the seed ; 2.6 : ostiolar region (micropyle), middle part and lower part of the seed-enlarged ; 2.7: Vertical section at right angles to the flat seed-lower part enlarged ; 2.8: L.S. of the seed-middle part enlarged; 2.9, 2.10: outer and central zones enlarged 
Sclerotic seed coat: The seed coat comprised of sclerenchyma cells was seen in the surface view. The cells were small, polygonal, thick walled and lignified. (Figure 3.3)

Parenchymatous seed coat in cut view: Parenchymatous seed coat appeared in T. S. view or transversely cut view. (Figure: 3.4). In this view, there were few layers of sclerenchyma cells and wide zone of parenchyma cells. Some of the parenchyma cells were in radial parallel files. The cells were thick walled and compact.

Sectional view of full seed coat: The parenchyma cells of the seed coat were radially oblong and thick walled. The inner sclerenchyma zone abruptly started to form a thick band of sclerenchyma cells. There was an inner layer of two to three layers of sclereids which were also thick walled and lignified. (Figure 3.5)

Oil bodies (Figure 3.6): Spherical shaped oil bodies of various sizes were abundant in the powder which were stained red with Sudan-III stain. These were located in the remnants of endosperm and in the cells of the embryo.

Small clusters of seed coat sclereids were very common in the powder. The sclereids were also seen as isolated cells. (Figure 3.6, 3.7) They were either circular or polygonal in outline with wide cell lumen and thick lignified walls. Simple canal like pits were also seen on the walls.

\section{Physicochemical parameters}

The quality control parameters for the seeds were established with the help of physicochemical parameters. (Table: 1 )

\section{Fluorescence analysis}

Fluorescence analysis imparted characteristic colours to the seed powder when observed under visible and UV light. (Table: 2 )

\section{Preliminary phytochemical screening}

Preliminary phytochemical screening revealed the presence of flavonoids, terpenoids carbohydrates, oils and fats, saponins and tannins.

\section{Acute toxicity studies}

Selection of the dose regimen i.e., 200 and $400 \mathrm{mg} / \mathrm{kg}$, b.w. as lower and higher doses was based on acute toxicity studies carried out by following OECD 423 guidelines.

\section{Effect of extract on serum parameters}

Table 3 showed that single intra-peritoneal administration of $5 \mathrm{mg} / \mathrm{kg}$, b.w. of Cisplatin induced significant rise in serum creatinine, total protein and blood urea nitrogen levels in the Cisplatin treated rats (Group II and Group V). However, elevations in the levels of serum creatinine, total protein and blood urea nitrogen were significantly attenuated by pre and post treatment with the hydroalcoholic extract of Trichosanthes cucumerina in dose related fashion. (Table 3)

\section{Effect of hydroalcoholic extract on urinary parameters}

Cisplatin administered rats (control group) had encountered acute kidney dysfunction as evidenced by elevation in the levels of urinary creatinine and urinary proteins. Treatment with the hydroalcoholic extract of Trichosanthes cucumerina at the dose level of $400 \mathrm{mg} / \mathrm{kg}$,b.w. for 5 days (Group-IV) significantly lowered the levels of creatinine and proteins when compared with the toxic control group. (Table 4)

\section{Effect of hydroalcoholic extract on anti-oxidant}

\section{parameters}

Dose dependent decrease in LPO levels and increased levels of catalase, superoxide dismutase, glutathione also substantiated the nephroprotective activity of extract. (Figure 4)

\section{Histopathological studies}

In histopathological studies cisplatin-induced nephrotoxicity was indicated by degenerative changes in kidney tissues whereas marked regenerative changes were observed in higher dose treated animals. (Figure 5)

\section{DISCUSSION}

Taking into examination the tremendous upsurge of worldwide attention in medicinal plants and their products in the past decade, the World Health Organization (WHO) has recognized the prominence of Traditional System of Medicine (TSM). ${ }^{23}$ India has an extensive history of herbal medicine. Ayurveda is the oldest and most widely practiced system of medicine, which includes entire plants or their parts, namely, the root, stem, bark, leaves, flowers, fruits, seed, the exudates, etc., as the major portion of drugs, in various formulations. The therapeutic efficacy of drugs used in various systems greatly relies on the use of proper and genuine raw materials. Because of these, assurance of safety, quality, and efficacy of medicinal plants has now become a main issue. ${ }^{24}$

The important histological findings in case of seed powder of Trichosanthes cucumerina suggest that there is presence of spherical shaped oil bodies stained with Sudan-III. Another characteristic feature of the powder is circular or polygonal sclereids, simple canal like pits, wide cell lumen and thick lignified walls. These can be considered as distinguishing characteristic for powder microscopy of the plant.

Microscopic features are the valuable characteristics for the establishment of identity of the plant. ${ }^{25}$ In Microscopic studies T. S. of the seed showed that the seed coat had outer aerenchymatous tissue, inner parenchymatous tissue and innermost compact lines of sclereids. In transverse section seed had 2 flat parallel cotyledons with thin walled parenchyma cells, innermost parenchymatous sarcotesta with vascular strands composed of xylem and phloem elements. More direct contamination, such as by sand or earth, is immediately detected by the ash value. Total ash, acid insoluble ash and water soluble ash values were 7.15, 6.45 and 0.5 respectively.

Extractive values are used in qualitative as well as quantitative estimation of phytoconstituents which act as a preliminary information about the drug. Physicochemical evaluation yielded alcohol and water soluble extractive values of 20.8 and $8.05 \%$ w/w which signify the nature of the phyto constituents present in plant. Deterioration depends upon the moisture content of the drug. If the water content is high, drug can be easily deteriorated due to fungus. The moisture content of the drug was found to be $5.26 \% \mathrm{w} / \mathrm{w}$ which signifies that the drug was properly dried and properly stored. The $\mathrm{pH}$ was 5.70 for $1 \%$ solution and 5.78 for $10 \%$ solution which was in weakly acidic range and may be because of weakly acidic salts present in the drug.

Fluorescence analysis is a necessary parameter for first line standardization of crude drug. ${ }^{26}$ In fluorescence the fluorescent light is always of greater wavelength than the exciting light. Light rich in short wavelengths is very active in producing fluorescence and for this reason ultraviolet light produces fluorescence in many substances which do not visibly fluoresce in daylight.

The preliminary phytochemical investigation of seed extract was performed which revealed the presence of triterpenoids, saponins, flavonoids, tannins, oils and fats. 
Table 1: Physico-chemical parameters for the seeds

\begin{tabular}{ccc}
\hline SL.No. & Parameters & Result \\
\hline 1. & Total ash content $(\% \mathrm{w} / \mathrm{w})$ & 7.15 \\
2. & Acid insoluble ash $(\% \mathrm{w} / \mathrm{w})$ & 6.45 \\
3. & Water soluble ash $(\% \mathrm{w} / \mathrm{w})$ & 0.50 \\
4. & Alcohol soluble extractive & 20.80 \\
5. & Water soluble extractive & 8.05 \\
6. & Moisture content $(\% \mathrm{w} / \mathrm{w})$ & 5.26 \\
7 & $\mathrm{pH}$ for $1 \%$ solution & 5.70 \\
8 & $\mathrm{pH}$ for $10 \%$ solution & 5.78 \\
\hline
\end{tabular}

Table 2: Fluorescence analysis

\begin{tabular}{ccc}
\hline Powdered drug & Visible/day light & Ultraviolet light \\
\hline Powder as such & Brown & Greenish brown \\
Extract as such & Dark brown & Greenish brown \\
Powder+ distilled water & Brown & Brown \\
Powder+ ammonia & Yellow & Greenish yellow \\
Powder+ conc. HCl & Black & Black \\
Powder+ picric acid & Yellowish white & Greenish white \\
Powder+ aqueous NaOH & Brown & Greenish brown \\
Powder+ aqueous $\mathrm{KOH}$ & Whitish brown & Greenish brown \\
Powder+ conc. H2SO4 & Brownish black & Greenish black \\
Powder+ chloroform & Brownish green & Brownish green \\
Powder+ alcoholic KOH & Yellowish brown & Greenish brown \\
Powder+ dilute $\mathrm{HCl}$ & Reddish brown & Light brown \\
Powder+ methanol & Light brown & Green \\
\hline
\end{tabular}

Table 3: Effect of hydroalcoholic extract of seeds of Trichosanthes cucumerina against Cisplatin-induced nephrotoxicity on serum parameters

\begin{tabular}{cccc}
\hline Treatment Groups & BUN $(\mathrm{mg} / \mathrm{dl})$ & $\mathrm{SC}(\mathrm{mg} / \mathrm{dl})$ & $\mathrm{S}_{\mathrm{TP}}(\mathrm{g} / \mathrm{dl})$ \\
\hline Normal & $16.87 \pm 0.22$ & $0.73 \pm 0.03$ & $5.92 \pm 0.13$ \\
Curative control & $29.6 \pm 0.70 \#$ & $1.67 \pm 0.05 \#$ & $8 \pm 0.14 \#$ \\
Curative lower dose & $23.97 \pm 0.72^{*}$ & $1.06 \pm 0.08^{*}$ & $7.12 \pm 0.20^{*}$ \\
Curative higher dose & $17.47 \pm 0.60^{*}$ & $0.88 \pm 0.06^{*}$ & $5.98 \pm 0.10^{*}$ \\
Prophylactic control & $34.73 \pm 0.77 \#$ & $1.62 \pm 0.09 \#$ & $8.35 \pm 0.15 \#$ \\
Prophylactic Lower dose & $25.88 \pm 0.67^{*}$ & $1.18 \pm 0.05^{*}$ & $7.13 \pm 0.3^{*}$ \\
Prophylactic Higher dose & $21.55 \pm 0.57^{*}$ & $0.95 \pm 0.06^{*}$ & $6.02 \pm 0.1^{*}$ \\
Standard & $17.43 \pm 0.5$ & $0.78 \pm 0.05$ & $6.0 \pm 0.1$ \\
\hline
\end{tabular}

Each value represents the Mean \pm S.E.M from 6 animals in each group. ; $\# \mathrm{P}<$ $0.05 \mathrm{Vs}$ normal group ; ${ }^{*} \mathrm{P}<0.05 \mathrm{Vs}$ control group

The plant is richly constituted with a series of chemical constituents like flavonoids, terpenoids, saponins which makes the plant pharmacologically and therapeutically active. ${ }^{27}$

Many of the plants having secondary metabolites rich in anti-oxidant principles are evidenced to be precursors for development of other drugs. Further many more allopathic drugs have their origin in plant extracts. In ancient literature seeds of Trichosanthes cucumerina are prescribed for the treatment of renal disorders. Hence the present research was focussed on pharmacological evaluation of seeds of Trichosanthes cucumerina for nephroprotective activity. With the administration of
Table 4: Effect of hydroalcoholic extract of seeds of Trichosanthes cucumerina against Cisplatin-induced nephrotoxicity on urinary parameters:

\begin{tabular}{ccc}
\hline Treatment Groups & $\mathrm{U}_{\mathrm{cr}}(\mathrm{mg} / \mathrm{dl})$ & $\mathrm{U}_{\mathrm{TP}}(\mathrm{g} / \mathrm{dl})$ \\
\hline Normal & $3.28 \pm 0.03$ & $4.02 \pm 0.12$ \\
Curative control & $0.73 \pm 0.02^{\#}$ & $13.15 \pm 0.23 \#$ \\
Curative lower dose & $1.72 \pm 0.03^{*}$ & $9.03 \pm 0.22^{*}$ \\
Curative higher dose & $3.18 \pm 0.02^{*}$ & $5.65 \pm 0.18^{*}$ \\
Prophylactic control & $0.67 \pm 0.01 \#$ & $17.35 \pm 0.28 \#$ \\
Prophylactic Lower dose & $1.89 \pm 0.02^{*}$ & $10.20 \pm 0.23^{*}$ \\
Prophylactic Higher dose & $2.71 \pm 0.03^{*}$ & $6.55 \pm 0.19^{*}$ \\
Standard & $3.22 \pm 0.01$ & $4.98 \pm 0.19$ \\
\hline
\end{tabular}

Each value represents the Mean \pm S.E.M from 6 animals in each group.; \# $\mathrm{P}<$ $0.05 \mathrm{Vs}$ normal group ; ${ }^{\star} \mathrm{P}<0.05 \mathrm{Vs}$ control group

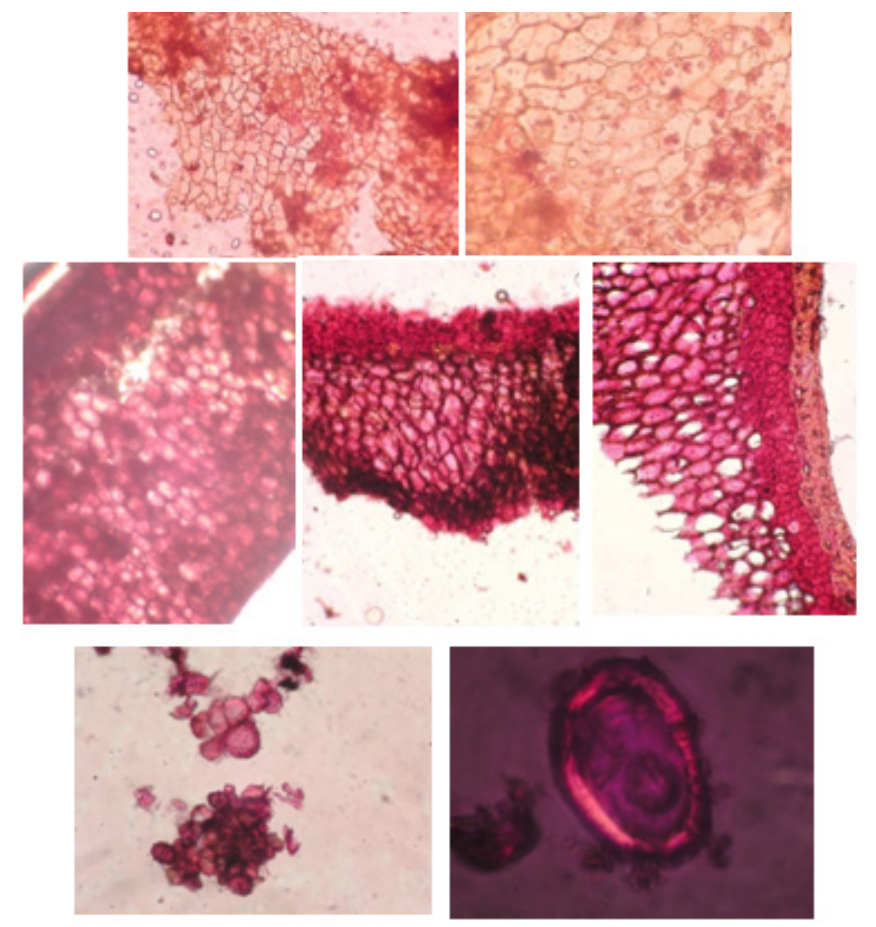

Figure 3.1: Parenchyma cells of the seed coat ; 3.2: Oil bodies in the cells ; 3.3: seed coat in surface view ; 3.4 : Part of the seed coat in sectional view ; 3.5 : T.S. view of the seed coat

3.6:seed coat sclereids ; 3.7:single sclereid-enlarged

single dose of Cisplatin, approximately in one-third of the patients nephrotoxicity advances. ${ }^{2}$ Nephrotoxicity was induced by cisplatin with a single dose of $5 \mathrm{mg} / \mathrm{kg}$ b.w. intraperitoneally. ${ }^{3}$ So it is very crucial to prevent and manage the acute renal failure.

Cisplatin, an inorganic platinum based chemotherapeutic agent is widely in use in the treatment of a variety of tumours such as head and neck, lung, testis, ovarian and bladder cancers. But its usage is often limited by various prominent side effects like bone marrow suppression, peripheral neuropathy, anaphylaxis, ototoxicity and nephrotoxicity. Various studies have revealed that cisplatin induces apoptosis or necrosis in the kidney cells by reduction in ATPase activity and induction of cell cycle arrest and also disruption of renal tubular cell transport systems. ${ }^{28}$ Other mechanisms of cisplatin-induced kidney injury comprise inflammation, fibrogenesis, and oxidative stress. ${ }^{29}$ 
LIPID PEROXIDA TION (MDA LEVELS)

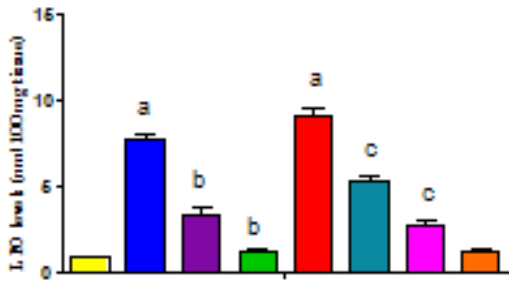

CATALASE
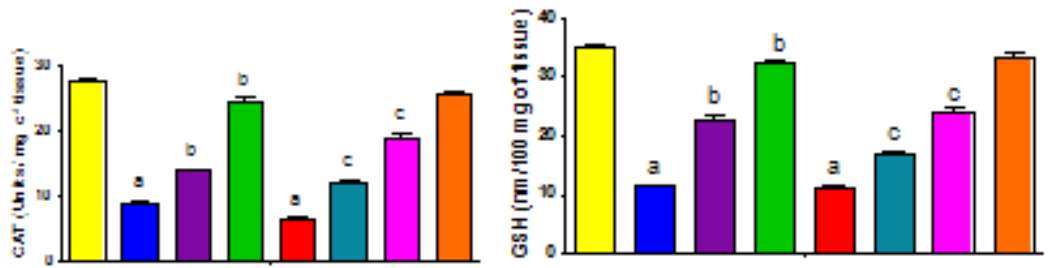

Figure 4: Graphs for anti-oxidant studies $a$ is $<0.05$ when compared to normal $b$ is $<0.05$ when compared to curative control c is $<0.05$ when compared to prophylactic control
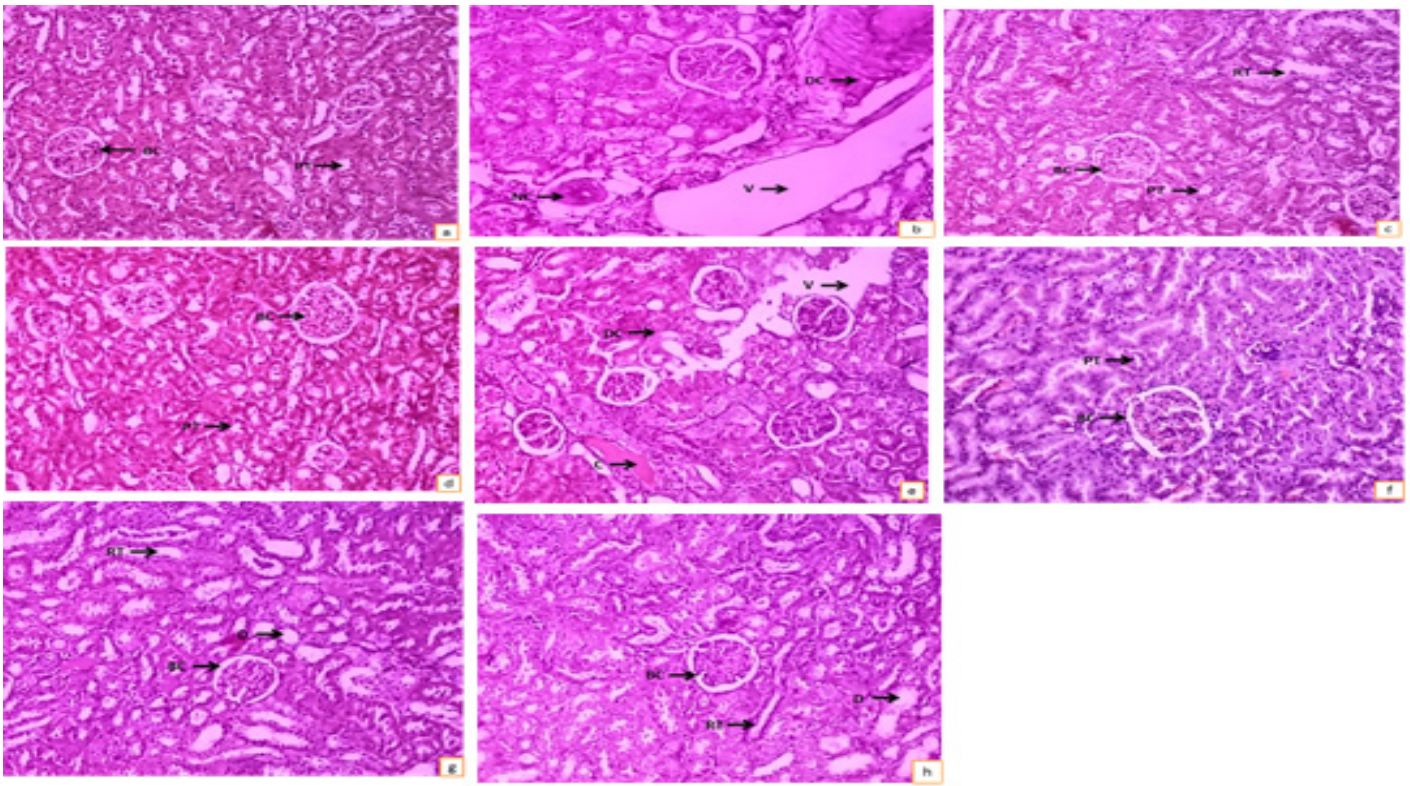

a) Group-I: Photomicrograph of histological section of rat kidney showing the normal architecture of glomeruli (normal group).

b) Group-II: Photomicrograph of histological section of kidney treated with Cisplatin only (Curative control) showing necrotic changes and vacuolization with haemorrhage.

c) Group-III: Photomicrograph of histological section of kidney treated with $200 \mathrm{mg} / \mathrm{kg}$, b.w. of the extract with mild regeneration of the kidney tissue with lower magnification (Curative lower dose).

d) Group-IV: Photomicrograph of histological section of kidney treated with $400 \mathrm{mg} / \mathrm{kg}$, b.w. of the extract showing significant regenerative changes with almost normal cyto-architecture (Curative higher dose).

e) Group-V: Photomicrograph of histological section of kidney treated with Cisplatin only (prophylactic control) showing the degenerative changes in kidney with cytoplasmic vacuolization and degenerative Bowman's capsule.

f) Group-VI: Mild regenerative changes in kidney tissue of the rat treated with 200mg/kg, b.w. (Prophylactic lower dose). g) Group-VII: Kidney tissue showing regenerative changes in tubules and glomeruli treated with 400mg/kg, b.w. (Prophylactic higher dose).

h) Group-VIII: Regeneration of kidney tissue similar to normal cyto-architecture. (Standard) 
In recent years, use of natural remedies has advanced to reduce cisplatin nephrotoxic action. ${ }^{30-32}$ Among medicinal plants, Trichosanthes cucumerina because of various pharmacological properties and rich historical and religious background, taken into more consideration..$^{33}$ Therefore, in the present study we hypothesized that Trichosanthes cucumerina extract may protect the kidney against cisplatin-induced toxicity. Present study, in the line with Salama et al. and Tikoo et al. observations, demonstrated that cisplatin was significantly able to increase serum urea and creatinine concentration, which confirmed the accuracy of the experiment in induction of renal injury. ${ }^{34,35}$ The results of current study indicated that treatment with Trichosanthes cucumerina extract at $400 \mathrm{mg} / \mathrm{kg}$, b.w. significantly reduced the blood urea nitrogen and creatinine concentrations in curative treatment group.

It is well known that oxidative stress plays an important role in the pathogenesis of nephrotoxicity caused by drugs. In most cases of druginduced nephrotoxicity there will be generation of ROS, leading to oxidative damage, concomitant increase in serum markers and LPO ultimately causing depletion of renal GSH content and anti-oxidant armoury of kidney. ${ }^{36}$

Control group animals had exhibited profound increase in lipid peroxidation levels and decreased levels of superoxide dismutase, catalase and reduced glutathione, thus leading to oxidative stress. Conversely the extract normalized the lipid peroxidation levels and increased the levels of SOD, GSH and CAT. Treatment with extract prevented a rise in the MDA levels when compared to the control group kidneys. The protective effect of the extract could be partly due to the phyto-constituents present in the extract which may attribute to enhanced anti-oxidant levels.

In the present study, the dose dependent and time line curative potential of hydroalcoholic extract of Trichosanthes cucumerina was observed.

\section{CONCLUSION}

The experimental results obtained in curative regimen revealed that the nephroprotective activity of the extract is comparable to that of Cystone. The activity elicited by the extract might be due to the presence of active phytoconstituents like flavonoids, saponins and terpenoids which activate antioxidant enzymes. These data suggest that hydroalcoholic extract of Trichosanthes cucumerina can potentially be used to reduce Cisplatininduced nephrotoxicity, thereby enhancing the therapeutic window of cisplatin.

\section{ACKNOWLEDGEMENT}

It is a pleasure to acknowledge with gratitude the financial assistance provided by DST-WOS-A [SR/WOS-A/LS-425/2012 (G)] which made the implementation of the project work. Authors are also thankful to Head, IPT, SPMVV, Tirupati for providing necessary facilities to carry out the research work.

\section{CONFLICT OF INTEREST}

None

\section{ABBREVIATIONS USED}

I.P: intra-peritoneal; UTP: Urinary total proteins; UCR: Urinary creatinine; STP: Serum total proteins; AKI: Acute kidney injury; BUN: Blood urea nitrogen; SC: Serum creatinine; LPO: Lipid peroxidation; ROS Reactive oxygen species; SOD: Superoxide dismutase; GSH: Reduced glutathione; CAT: Catalase.

\section{REFERENCES}

1. Arshad Ali Noorani, Karan Ajay Gupta, Khusboo Bhadada, Kale M. K. Protective effect of methanolic leaf extract of Caesalpinia bonduc (L) on Gentamicin- in- duced hepatotoxicity and nephrotoxicity in rats. Iranian J Pharmacol and Ther. 2011;10:21-5.

2. Kroning R, Lichtenstein AK, Nagami GT. Sulfur-containing amino acids decrease cisplatin cytotoxicity and uptake in renal tubule epithelial cell lines. Cancer Chemother Pharmacol. 2000;45(1):43-9. https://doi.org/10.1007/PL00006741 PMid: 10647500

3. Mohamed M. E. Afifi. Effect of camel's milk on cisplatin-induced nephrotoxicity in Swiss albino mice. Am. J. Biochem. Biotechnol. 2010;6(2):141-7. https://doi. org/10.3844/ajbbsp.2010.141.147.

4. Kanchan Gaikwad, Pradeep Dagle, Pushpalata Choughule, Y. M. Joshi, Vilasrao Kadam. A review on some nephroprotective medicinal plants. International journal of Pharmaceutical Sciences and Researh IJPSR. 2012;3(8):2451-4.

5. Glidemacher BH, Jansen GJ, Chayamarit K. Plant resources of South-East Asia No 8. Vegetables, Trichosanthes L. In: Siemonsma JS Kasem P, Pudoc Scientific Publishers, Wageningen, Netherlands. 1993;271-4

6. Choudhury B. Vegetables, India, The land and the people National Book Trust, New Delhi, India. 1967;214-5.

7. Madhava KC, Sivaji K, Tulasi KR, Flowering Plants of Chittoor Dist A.P. India, Students Offset Printers, Tirupati. 2008;141.

8. Nadkarni KM, Indian materiamedica, Ed.2nd, Vol 1, Popular Prakashan, Mumbai 2002;1(2):1235-6.

9. KR Khandelwal. Practical Pharmacognosy Techniques and Experiments. 15th ed., Pune, NiraliPrakashan. 2006;pp.15-163.

10. CK Kokate. Practical Pharmacognosy, $4^{\text {th }}$ ed., Delhi, VallabhPrakashan. 1997;4:107-11. PMid:9050410.

11. TE Wallis. Text Book of Pharmacognosy. $5^{\text {th }}$ ed., Delhi, CBS publishers and Distributors. 2005;5:104-58.

12. Johansen DA. Plant Micro technique, McGraw Hill Book Company Inc.; New York. 1940,;pp.523.

13. O' Brien TP, Feder N, Mc Cull ME. Polychromatic staining of plant cell walls by toluidine blue-O. J. Protoplasma. 1964;59(2):364-73. https://doi.org/10.1007/ BF01248568.

14. Esau K. Plant Anatomy. John Wiley and Sons, New York. 1964;767.

15. Chase CR, Pratt RJ. Flourescence Analysis J. Am. Pharm. Assoc. (Sci.Eds.) 1949;38:324-31.

16. Harborne J B, Phytochemical Methods. Chapman \& Hall: International Edition, Japan: Toppan Company Ltd. 1973;pp:49-188.

17. OECD/ OCDE, OECD guidelines for testing of chemicals, Acute oral toxicityAcute toxicity class method, 423. Adopted 17th December, 2001.

18. Godkar PB. Kidney function tests. In: Text book of Medicinal laboratory. Bombay: Bhalani publishing house. 1994:1022-8.

19. Cohen, D., Dembiec, D., Marcus, J., 1970. Measurement of catalase activity in tissue extracts. Annals Biochemistry. 1970;34(1):30-8. https://doi. org/10.1016/0003-2697(70)90083-7.

20. Saggu H, Cooksey J, Dexter, DA. Selective increase in particulate super oxide dismutase activity in Parkinsonian subtansia nigra. J. Neurochem. 1989;53(3):692-7. https://doi.org/10.1111/j.1471-4159.1989.tb11759.x.

21. Ellman, Georg L. Tissue sulfahydryl group. Arch. Biochem. Biophys. 1959;82:70 7. https://doi.org/10.1016/0003-9861(59)90090-6.

22. World Health Organization (WHO). Traditional Medicine. 2008, WHO Fact Sheet No.134. Geneva: WHO revised 2003. ( accessed 11 December 2008).

23. Upadhye AS, Deshpande AS. Microscopic Profile of Drugs Used in Indian Systems of Medicine: Seed Drugs. J Ayurveda Integr Med. 2012;3(2):105-6.

24. Komlaga, G., Sam, G.H. Dickson, R. A, Mensah, M.L.K.2, Fleischer, T. C. Pharmacognostic studies and antioxidant properties of the leaves of Solanum macrocarpon. J. Pharm. Sci. \& Res. 2014.6(1):1-4.

25. Prasad VK, Ramesh SD, et al., Pharmacognostic, phytochemical and physicochemical studies of Mimusops elengi Linn stem bark (Sapotaceae). Der Pharmacia Lettre, 2012;4(2):607-13.

26. Adeboye OC. Phytoconstituents and anti-oxidant activity of the pulp of snake tomato Trichosanthes cucumerina (L). Afr. J. Tradit. Compliment. Altern. Med. 2008;5:173-9.

27. Razzaque MS. 2007. Cisplatin nephropathy: is cytotoxicity avoidable? Nephrol Dial Transplant. 2007;22(8):2112-6. https://doi.org/10.1093/ndt/gfm378 PMid:17617652

28. Yao,X., Panichpisal, K., Kurtzman, N., Nugent, K., 2007. Cisplatin nephrotoxicity: a review. Am. J. Med. Sci. 2007;334(2):115-24. https://doi.org/10.1097/ MAJ.0b013e31812dfe1e PMid:17700201.

29. Antunes LMG, Darin JDC, Bianchi LMP. 2001. Effects of the antioxidants curcumin or selenium on cisplatin-induced nephrotoxicity and lipid peroxidation in rats. Pharmacol Rese. 2001;43(2):145-50. https://doi.org/10.1006/ phrs.2000.0724 PMid:11243715.

30. Kim YH, Kim YW, Oh YJ, Back N, Chung SA, Chung HG, Jeong TS, Choi MS, Lee KT. 2006. Protective effect of the ethanol extract of the roots of Brassica rapa on cisplatin-induced nephrotoxicity in LLCPK1 cells and rats. Biol Pharm Bull. 2006;29(12):2436-41. https://doi.org/10.1248/bpb.29.2436 PMid:17142978.

31. Shimeda Y, Hirotani Y, Akimoto Y, Shindou K, ljiri Y, Nishihori T, Tanaka K. 2005. 
Protective effects of Capsaicin against cisplatin-induced nephrotoxicity in rats. Biol Pharm Bull. 2005;28(9):1635-8. https://doi.org/10.1248/bpb.28.1635 PMid:16141530

32. Ahmad A, Husain A, Mujeeb M, Alam Khan S, Najmi AK, Siddique NA, Damanhouri ZA, Anwar F. 2013. A review on therapeutic potential of Nigella sativa: A miracle herb. Asian Pac J Trop Biomed. 2013;3(5):337-52. https://doi. org/10.1016/S2221-1691(13)60075-1.

33. Tikoo K, Bhatt DK, Gaikwad AB, Sharma V, Kabra DG. Differential effects of tannic acid on cisplatin- induced nephrotoxicity in rats. FEBS Lett. 2007;581(10):2027-
35. https://doi.org/10.1016/j.febslet.2007.04.036 PMid:17470369.

34. Salama RHM, Abd-El-Hameed NA, Abd-ElGhaffar SKH, Mohammed ZT, Ghandour NMA. Nephroprotective effect of Nigella sativa and Matricaria chamomilla in Cisplatin-induced renal injury. Int J Clin Med. 2011;2(3):185-95. https://doi. org/10.4236/ijcm.2011.23031.

35. Shiekh TA, Wani A, Amlesh S, Sana N, Summya R, Nemat A, et al. Preclinical renal cancer chemo preventive efficacy of geraniol by modulation of multiple molecular pathways. Toxicol. 290;(2011):69-81. https://doi.org/10.1016/j. tox.2011.08.020 PMid:21907755.

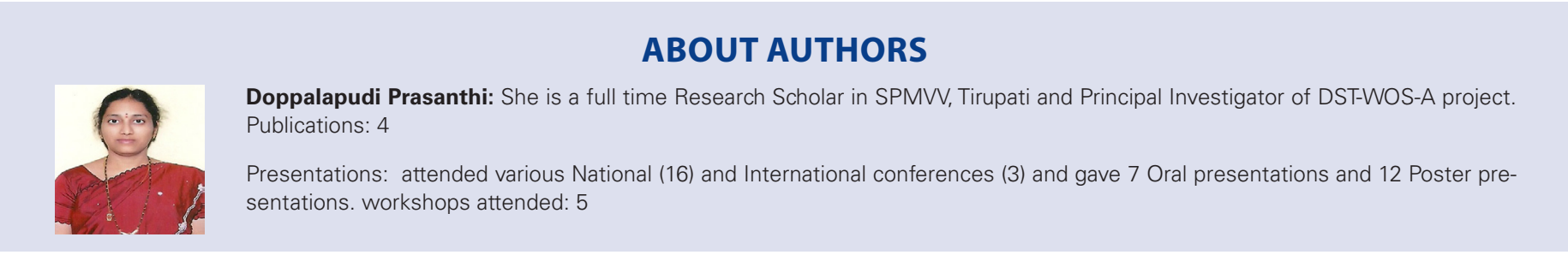

Cite this Article: Prasanthi D, Adikay S. Pharmacognostic Studies and Nephroprotective Potential of Hydroalcoholic Extract of Trichosanthes cucumerina in Acute Renal Failure. Pharmacogn J. 2017;9(2):176-84. 